\title{
Fincar a bandeira caeté na ágora mundializada
}

\author{
José Marques de Melo
}

\section{SciELO Books / SciELO Livros / SciELO Libros}

MELO, JM. Cidadania glocal, identidade nordestina: ética da comunicação na era da internet [online]. Campina Grande: EDUEPB; Latus, 2011. 108 p. ISBN 978-85-63984-07-4. Available from SciELO Books $<\underline{\text { http: } / / \text { books.scielo.org }>\text {. }}$

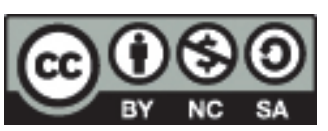

All the contents of this work, except where otherwise noted, is licensed under a Creative Commons Attribution-Non Commercial-ShareAlike 3.0 Unported.

Todo o conteúdo deste trabalho, exceto quando houver ressalva, é publicado sob a licença Creative Commons Atribuição Uso Não Comercial - Partilha nos Mesmos Termos 3.0 Não adaptada.

Todo el contenido de esta obra, excepto donde se indique lo contrario, está bajo licencia de la licencia Creative Commons Reconocimento-NoComercial-CompartirIgual 3.0 Unported. 


\section{Fincar a bandeira caeté na ágora mundializada ${ }^{10}$}

O Pensamento Comunicacional Alagoano configura-se como expressão intelectualizada do fenômeno sociocultural engendrado pelo desenvolvimento da imprensa em nosso território. Ele acompanhou, em certo sentido, os marcos fincados pelo Pensamento Brasileiro, que se esboça institucionalmente na metade do século XIX e assume legitimidade acadêmica na metade do século XX.

Estruturado a partir de 1874, o Pensamento Alagoano tem como solo fértil o espaço investigativo construído pelo Instituto Archeológico

10 Alocução proferida em Maceió, no dia 26 de fevereiro de 2003, perante o Conselho Universitário da Universidade Federal de Alagoas, durante a solenidade de outorga do título de Doutor Honoris Causa 
e Geográfico Alagoano, depois transformado em Instituto Histórico e Geográfico de Alagoas. Seus principais artífices pertencem a essa instituição centenária. Constituída durante muito tempo na principal ágora alagoana, a hegemonia do IHGA vem sendo partilhada, na segunda metade do século $X X$, com a Universidade Federal de Alagoas e outras entidades similares ou correlatas.

Ao revisar a bibliografia alagoana, vislumbramos duas vertentes bem nítidas na configuração do seu Pensamento Comunicacional:

1. CORRENTE TELÚRICA - formada pelos estudiosos que esboçaram processos cognitivos ou elucidaram enigmas peculiares aos fenômenos comunicacionais da terra. Trata-se de uma plêiade fincada no território provincial, naturalmente motivada pelas circunstâncias típicas e tópicas do nosso cotidiano regional. Sua vivência marca intensamente os perfis das respectivas trajetórias intelectuais. Representantes emblemáticos: Dias Cabral, Pereira Diegues, Craveiro Costa, Abelardo Duarte, Medeiros Sant'Anna

2. DIÁSPORA CAETÉ - constituída por intelectuais alagoanos que foram compelidos, por distintas razões, a migrar para outras plagas, sem, contudo, 
perder sua identidade regional. Eles dedicaram energias e emoções para estudar os fenômenos comunicacionais da sua época, refletindo ao mesmo tempo sobre o impacto provocado na vida das gerações a que pertencem. Representantes emblemáticos: Octávio Brandão, Costa Rego, Raul Lima, Tadeu Rocha, José Augusto Guerra, Arnoldo Jambo, Ricardo Ramos, Reinaldo Santos, Audálio Dantas.

Quem produziu conhecimento comunicacional relevante, integrando cada um dos segmentos?

Corrente telúrica - Essa corrente tem como locus principal o Instituto Histórico Alagoano, instituição pioneira na investigação das raízes da sociedade alagoana.

Seus inventários, análises e interpretações dos fenômenos culturais da terra priorizam evidentemente a comunicação de massa - especialmente a imprensa - embora não marginalizando fenômenos singulares como aqueles situados no âmbito da folkcomunicação ou da comunicação erudita. Merecem destaque:

DIAS CABRAL, João Francisco, autor do primeiro inventário da imprensa alagoana, escrito, em 1870, como comunicação aos membros do IHGA: Acerca da fundação e desenvolvimento da imprensa nas Alagoas! 
Revista do Instituto Archeológico e Geográfico Alagono, N. 5, Maceió, Typografia do Jornal das Alagoas, 1874, p. 99-109.

Filiado à corrente histórica antilusitana, então vigente no país, condena a obtusidade da colonização portuguesa pelos obstáculos criados à implantação precoce da imprensa e enaltece a tentativa feita pelos invasores holandeses no século XVII. Além de haver delineado o perfil da atividade comunicacional pública, fez incursões através de outros processos comunicacionais, situados na fronteira daqueles fenômenos rotulados por Luiz Beltrão como folkcomunicacionais. Ele realizou trabaIhos de campo destinados a resgatar as contribuições negras e indígenas para a construção de símbolos que forjaram a identidade cultural alagoana.

Alagoas tem uma dívida intelectual com Dias Cabral, primeiro secretário perpétuo do IHGA. Reconhecido como "sábio" por seus contemporâneos, ele peregrinou por diversos territórios cognitivos, legando às novas gerações uma cartografia da cultura alagoana, a ser explorada, aprofundada e continuada.

CRAVEIRO COSTA escreveu Cem anos de jornalismo - Memória histórica sobre o jornalismo em Alagoas, Revista do Instituto Archeológico e Geográfico Alagoano, ano 58, 
vol. 15, Maceió, Oficinas Gráficas da Livraria Machado, 1931, p. 78-130

Trata-se de uma atualização dos inventários precedentes de Dias Cabral e Pereira Diegues, tendo, contudo, uma estatura analítica diferenciada. Sua visão supera o caráter documental dos estudos pioneiros, oferecendo uma contextualização do desenvolvimento da imprensa alagoana. Além de situá-lo no panorama histórico cultural da província, faz extrapolações reflexivas, configurando uma espécie de pensamento crítico, o que não significa sua exclusão do quadro das paixões provincianas, a que o autor sucumbe de modo inexorável.

Craveiro Costa reconhece nitidamente

a imprensa como degrau para a política ou para a ascensão social em outras esferas da sociedade. Eis uma hipótese de trabalho a ser retomada pelas novas gerações, verificando quanto, como ou se mudou essa situação nos últimos 70 anos.

MEDEIROS DE SANT'ANNA, Moacir Autor da mais consistente e persistente contribuição ao resgate da trajetória da imprensa alagoana, é autor de uma alentada bibliografia. Sua contribuição à História da Imprensa Alagoana está dividida em dois segmentos: Comunicação pública - A imprensa oficial em Alagoas, Maceió, Arquivo Público de Alagoas, 1962, 38 p. e História da Imprensa em 
Alagoas, Maceió, Arquivo Público de Alagoas, 1987, 236 p.Comunicação erudita - História do Modernismo em Alagoas, Maceió, EDUFAL, 1980, 228 p. e As leituras do jovem Graciliano Ramos, Maceió, Secretaria de Comunicação Social, 1992, 31 p.

Seus trabalhos representam um manancial precioso de referências históricas e de marcos analíticos, capazes de suprirem as expectativas das novas gerações que se dedicam ao estudo dos fenômenos comunicacionais na universidade.

Ao registrar sua presença no ápice da pirâmide demarcada pela corrente telúrica, 102 torna-se indispensável valorizar sua luta pela preservação da memória da nossa imprensa. Enfrentando todas as adversidades, ele vem recuperando as coleções de jornais, revistas e livros constantes dos acervos do IHGA e do Arquivo Público, além de promover edições fac-similadas que democratizam o acesso às fontes do conhecimento histórico.

Diáspora caeté - Certamente esse grupo de exilados involuntários, que não encontraram ambiente propício para crescer intelectualmente na terra natal, tendo que lutar pela sobrevivência em outros territórios da geografia nacional, sem perder a identidade caeté, deveria ter na sua dianteira TAVARES BASTOS. 
Esse intelectual alagoano de fama nacional cedo ausentou-se da província, projetando-se intelectualmente na Corte Imperial, durante o Segundo Reinado.

A ele é atribuída a condição de PRIMEIRO JORNALISTA BRASILEIRO, por ter exercido esse ofício com autonomia intelectual e independência política, atributos negados aos pioneiros "oficiais": no ambiente áulico, o editor da Gazeta do Rio de Janeiro, Frei Tibúrcio, submetido à censura monárquica; nas margens anticolonialistas, o editor do Correio Braziliense, Hipólito José da Costa, livre do jugo da censura lusitana, embora dependente do patrocínio imperial inglês e do amparo político maçônico.

Seu pensamento comunicacional está metaforicamente implícito no personagem que criou para intervir no espaço público sem sofrer as consequências da "lei da mordaça" daquela época. Ele preservou sigilosamente sua identidade durante o processo, descortinando posteriormente a autoria das Cartas do Solitário, quando elas esmaeceram nas páginas do jornal e ganharam intensidade através do livro.

Ele poderia ser alcunhado, sem qualquer sentido pejorativo, de precursor dos factóides, engendrando um tipo de publicista capaz de ser amado ou combatido pelos leitores. 
Desvendando fatos relevantes e suscitando intensa polêmica, ele foi capaz de criar um espaço público na modorrenta paisagem da vida cotidiana dominante no período final do Império brasileiro.

Destacam-se também:

COSTA REGO - Primeiro catedrático de comunicação do Brasil, esse alagoano ilustre transitou com desenvoltura entre o jornalismo e a política, alternando a função pública como Deputado, Senador e Governador de Estado com o exercício profissional como redatorchefe do influente diário carioca Correio da Manhã.

Seu pensamento comunicacional está explicitado em três obras escritas em distintas conjunturas: Na terra natal, Maceió, Imprensa Oficial, 1928; Como foi que persegui a imprensa, Rio de Janeiro, 1930 e Águas passadas, José Olympio, 1952

A primeira contém um diagnóstico cáustico e irrefutável das fragilidades da imprensa alagoana num ambiente socioeconômico desfavorável ao seu desenvolvimento enquanto empresa privada. No segundo, ele descreve suas desavenças com os colegas de profissão enquanto foi Governador de Alagoas, por haver eliminado os subsídios governamentais aos jornais e aos jornalistas. No terceiro, ele discute cenários e personagens da imprensa brasileira, 
dialogando sobre censura e outros temas polêmicos com os governantes de turno.

ARNOLDO JAMBO - Profissional de grande destaque na imprensa alagoana das décadas de 50 e 60, quando ocupou a direção do Jornal de Alagoas, exercendo também a chefia do Departamento de Cultura do Estado de Alagoas, migrou para o Recife na década de 70. Publicou, em 1975, o livro intitulado Diário de Pernambuco: História e Jornal de Quinze Décadas, Recife, Diário de Pernambuco, 1975.

Trata-se de um bem arquitetado confronto entre a vida cotidiana do jornal, resgatada através de consulta minuciosa à coleção de edições publicadas, e os principais fatos históricos da região nordestina, nos 150 anos que abrangem o período 1825-1975.

O diferencial desta obra é o seu caráter propriamente jornalístico, esboçando o cotidiano do periódico a partir do seu interior, deixando de ser um retrato exógeno como tem sido comum em obras desse tipo escritas por historiadores.

À guisa de conclusão - Não posso fugir à contingência de situar-me no contexto do pensamento comunicacional alagoano, neste momento em que a Universidade Federal de Alagoas me honra com a concessão do diploma de Doutor Honoris Causa. Diletos colegas já vasculharam minha produção intelectual no 
Seminário hoje realizado sob o título "Memória da Pesquisa em Comunicação no Nordeste". Por isso mesmo, creio que não devo ir além de uma mera localização nesse panorama.

Pertenço evidentemente ao contingente da "diáspora caeté", tendo construído uma obra cujos marcos bibliográficos são os meus livros Comunicação Social: Teoria e Pesquisa (1970), Estudos de Jornalismo Comparado (1972), Sociologia da Imprensa Brasileira (1974) e A Opinião no Jornalismo Brasileiro (1985).

Contudo, mantive permanente identificação intelectual com a "corrente telúrica", resgatando o legado dos pioneiros, através da 106 leitura dos seus escritos, bem como testemunhando, mesmo à distância, a laboriosa ação daqueles que aqui resistiram bravamente.

Talvez, por essa razão, tenha sido procurado em São Paulo, por Théo Brandão, no início da década de 70, para discutir a ideia da criação de um Curso de Comunicação na Universidade Federal de Alagoas. Ofereci ao ilustre diretor do Instituto de Ciências Humanas da UFAL o manancial acumulado pela Escola de Comunicações e Artes da Universidade de São Paulo para servir como referência aos líderes da categoria dos jornalistas alagoanos, que reivindicavam a fundação do novo programa. Aceitei até mesmo um convite do Sindicato dos Jornalistas de Alagoas para vir a Maceió, 
na tentativa de convencer o Reitor Nabuco Lopes a acolher o projeto em debate. Sinto-me gratificado ao dizer que a iniciativa prosperou, avalizada por Nabuco Lopes e Theo Brandão, embora tramitando vagarosamente nas instâncias burocráticas, o que incluía o beneplácito do Ministério da Educação.

Criado o Curso de Comunicação na universidade pública, naturalmente a "corrente telúrica" experimentou uma mutação no seu locus produtivo. O IHGA deixou de ser protagonista exponencial, uma vez que o espaço de produção do novo conhecimento comunicacional alagoano passou a ser o Departamento de Comunicação Social da UFAL.

A nova geração que aqui está sendo formada certamente tem dado continuidade aos avanços cognitivos de ambas as vertentes que a precederam. A iniciativa de criar um curso de pós-graduação em comunicação, hoje confirmada pelo Reitor Rogério Moura Pinheiro, representa a culminância desse processo de atualização histórica do pensamento comunicacional alagoano.

Ao esboçar este roteiro intelectual no momento do meu reencontro com a alagoanidade, minha intenção não é outra senão oferecer aos colegas da UFAL um mapa cognitivo.

Ele pretende suscitar, neste início do século $X X I$, incursões investigativas comprometidas 
com a preservação e renovação do pensamento forjado por aqueles que ousaram plantar sementes, no século XIX, gerando árvores que se nutriram durante o século $X X$. Agora podemos colher os frutos e saboreá-los deliciosamente.

Resta, porém, o desafio de produzir novas matrizes, consentâneas com as demandas das gerações emergentes. Seus paladares estão aguçados pelas perspectivas de um mundo que se converte, pouco a pouco, em aldeia midiática.

Chegou o momento de fincar a bandeira caeté na ágora mundializada do ciberespaço ! 